\title{
rTMS modulates reciprocal inhibition in patients with traumatic spinal cord injury
}

\author{
R Nardone ${ }^{1,2,3}$, Y Höller ${ }^{1,3}$, A Thomschewski ${ }^{1,3}$, F Brigo $^{2,4}$, A Orioli ${ }^{2}$, P Höller ${ }^{1,3}$, \\ $S$ Golaszewski ${ }^{1,3}$ and E Trinka ${ }^{1,3}$
}

Study design: Randomized, double-blind, crossover, sham-controlled trial.

Objectives: Repetitive transcranial magnetic stimulation (rTMS) over the primary motor cortex (M1) leads to a significant reduction of spasticity in subjects with spinal cord injury (SCI), but the physiological basis of this effect is still not well understood. The purpose of this study was to evaluate the disynaptic reciprocal la inhibition of soleus motoneurons in $\mathrm{SCl}$ patients.

Setting: Department of Neurology, Merano, Italy and TMS Laboratory, Paracelsus Medical University, Salzburg, Austria.

Methods: Nine subjects with incomplete cervical or thoracic SCI received 5 days of daily sessions of real or sham rTMS applied over the contralateral M1. We compared the reciprocal inhibition, the Modified Ashworth Scale and the Spinal Cord Injury Assessment Tool for Spasticity at baseline, after the last session and 1 week later in the real rTMS and sham stimulation groups.

Results: We found that real rTMS significantly reduced lower limb spasticity and restored the impaired excitability in the disynaptic reciprocal inhibitory pathway.

Conclusions: In a small proof-of-concept study, rTMS strengthened descending projections between the motor cortex and inhibitory spinal interneuronal circuits. This reversed a defect in reciprocal inhibition after $\mathrm{SCl}$, and reduced leg spasticity.

Spinal Cord (2014) 52, 831-835; doi:10.1038/sc.2014.136; published online 12 August 2014

\section{INTRODUCTION}

Damage to the descending corticospinal pathways that exert spinal segmental control is thought to have an important causal role in the occurrence of spasticity after spinal cord injury (SCI).

High-frequency repetitive transcranial magnetic stimulation (rTMS) applied over the primary motor cortex (M1) was found to reduce $\mathrm{H}$-reflex size in healthy subjects, ${ }^{1}$ as well as spasticity in patients with multiple sclerosis ${ }^{2}$ or spastic quadriplegia due to cerebral palsy. ${ }^{3}$ A significant clinical improvement in lower limb spasticity was also observed in patients with incomplete SCI following active rTMS over M1. ${ }^{4}$ However, Kumru and colleagues surprisingly failed to find changes in the examined measures of corticospinal and segmental excitability (Hmax/Mmax, T reflex, and withdrawal reflex).

One of the spinal interneuronal circuits with crucial contribution to the neural control of movement is that of disynaptic reciprocal Ia inhibition. ${ }^{5,6}$ The activity in this disynaptic pathway from muscle spindle Ia afferents to motoneurones of the antagonist muscle pathway can be studied in humans by using the monosynaptic test reflex (H-reflex), and is demonstrated as short-latency depression of the H-reflex following a conditioning stimulation of the antagonist nerve. There is evidence of a central regulation of the disynaptic reciprocal Ia inhibition. ${ }^{6}$ The importance of the central control of this pathway has also been emphasized by the finding of its abnormal activity in patients with brain lesions.

Therefore, to further investigate the mechanisms of action of the rTMS at the segmental spinal level, we aimed to evaluate its effect on the disynaptic inhibition of soleus motoneurons in SCI patients.

We hypothesize that a strengthened signal transmission though descending corticospinal projections may lead to an increased excitability in the spinal interneuronal circuits of disynaptic reciprocal Ia inhibition.

\section{MATERIALS AND METHODS \\ Patients}

Nine subjects (mean age 45.7 years, range 28-68 years, eight males and one female, all right-handed) with chronic incomplete cervical or thoracic SCI, classified as grades C or D according to the American Spinal Cord Injury Association Impairment Scale, ${ }^{7}$ were enrolled in the study.

Inclusion criteria were: (i) spasticity affecting lower limbs with a Modified Ashworth Scale $(\mathrm{MAS})^{8}>1.5$; (ii) stable medical treatment for at least 1 week before and 1 week after the rTMS applications; (iii) ability to give informed consent and comprehend instructions; (iv) no contraindications to TMS such as metal head implants; (v) no concomitant neurological conditions, including any history of epilepsy and polyneuropathies; (vi) no joint-related limitation of passive range of movement; (vii) no advanced liver, kidney, cardiac or pulmonary disease; (viii) no history of significant alcohol or drug abuse. Exclusion criteria were: (i) the lack of tolerance to TMS; (ii) missing an rTMS session.

Clinical and demographic features of the patients are shown in Table 1.

The control group constituted of eight age-matched healthy subjects (mean age 44.4 years, range $25-69$ years, seven males and one female, all righthanded).

\footnotetext{
${ }^{1}$ Department of Neurology, Christian Doppler Klinik, Paracelsus Medical University, Salzburg, Austria; ${ }^{2}$ Department of Neurology, Franz Tappeiner Hospital, Merano, Italy; ${ }^{3}$ Spinal Cord Injury and Tissue Regeneration Center, Paracelsus Medical University, Salzburg, Austria and ${ }^{4}$ Department of Neurological, Neuropsychological, Morphological and Movement Sciences. Section of Clinical Neurology, University of Verona, Verona, Italy Correspondence: Dr R Nardone, Department of Neurology, Franz Tappeiner Hospital, Meran/o, Via Rossini, 5, 39012 Merano, Italy. E-mail: raffaele.nardone@asbmeran-o.it
}

Received 31 March 2014; revised 20 June 2014; accepted 13 July 2014; published online 12 August 2014 
Table 1 Clinical and demographic characteristics of the patients with spinal cord injury

\begin{tabular}{|c|c|c|c|c|c|c|c|c|c|}
\hline Patients & $\begin{array}{c}A \\
\text { (years) }\end{array}$ & $G$ & Aetiology & $\begin{array}{l}\text { Time since } \\
\text { SCl (years) }\end{array}$ & Level/ASIA & \multicolumn{2}{|c|}{$\begin{array}{l}\text { UL motor } \\
\text { score }\end{array}$} & \multicolumn{2}{|c|}{$\begin{array}{c}\text { LL motor } \\
\text { score }\end{array}$} \\
\hline 1 & 54 & $M$ & Disc prolapse & 17 & C6/D & 41 & 38 & 49 & 48 \\
\hline 2 & 42 & $\mathrm{~F}$ & Fracture & 13 & $C 7 / D$ & 42 & 42 & 44 & 46 \\
\hline 3 & 36 & $M$ & Fracture & 13 & $\mathrm{C} 5 / \mathrm{C}$ & 23 & 26 & 26 & 28 \\
\hline 4 & 44 & $M$ & Fracture & 10 & $\mathrm{C} 6 / \mathrm{C}$ & 25 & 24 & 20 & 19 \\
\hline 5 & 28 & $M$ & Fracture & 8 & $C 7 / D$ & 46 & 42 & 32 & 29 \\
\hline 6 & 68 & $M$ & Disc prolapse & 5 & Th10/D & & & 48 & 45 \\
\hline 7 & 52 & $M$ & Fracture & 11 & Th8/C & & & 26 & 25 \\
\hline 8 & 38 & $M$ & Fracture & 4 & Th4/C & & & 24 & 22 \\
\hline 9 & 49 & $M$ & Fracture & 13 & Th8/D & & & 37 & 40 \\
\hline
\end{tabular}

Abbreviations: A, age; ASIA, American Spinal Injury Association Impairment Scale; G, gender; $\mathrm{LL}$, lower limb; SCI, spinal cord injury; UL, upper limb.

Patients and control subjects provided informed consent before participating in this study, which was performed according the Declaration of Helsinki and approved by the local Ethics Committee.

\section{Clinical evaluation of spasticity}

We used MAS (knee extensors) and the Spinal Cord Injury Assessment Tool for Spasticity (SCAT). ${ }^{9}$ The study was limited to the leg contralateral to the dominant hemisphere (thus the right leg).

\section{Neurophysiological evaluation}

H-reflex. Surface electrodes were used for both stimulation and recording electromyographic (EMG) activity. The soleus motor action potential (M-wave) and H-reflex were evoked by stimulating the tibial nerve through a monopolar stimulating electrode (1-ms rectangular pulse) at the popliteal fossa. The size of the control H-reflex was in all situations adjusted to $20-25 \%$ of Mmax (the maximal M-response). The $\mathrm{H}$-reflex responses were measured as the peak-to-peak amplitude of the non-rectified H-reflex. The H-reflexes were recorded by silver-silver chloride disc electrodes placed over the soleus muscle. The EMG signal was amplified $(1 \mathrm{mV} /$ division) and band-pass filtered $(2-10.000 \mathrm{~Hz})$.

Conditioning stimulation of the peroneal nerve. Reciprocal inhibition of the soleus H-reflex was measured by averaging the rectified EMG following conditioning stimulation of the peroneal nerve. The H-reflex was conditioned by stimulation of the peroneal nerve (rectangular 1-ms pulse) by bipolar surface electrodes placed $1-3 \mathrm{~cm}$ distal to the neck of the fibula. The conditioning stimulus strength was expressed in multiples of the M-threshold $(\times \mathrm{MT})$ in the tibialis anterior $(\mathrm{TA})$ muscle and was kept at $1.0 \times \mathrm{MT}$. In all subjects, the effect of peroneal nerve stimulation on the soleus H-reflex was investigated at rest. The conditioning-test interval was set at $2 \mathrm{~ms}$.

$r T M S$ protocol and experimental design. Patients were initially randomized to undergo either real rTMS (four patients) or sham rTMS (five patients).

Of the five patients who underwent sham rTMS first, four were subsequently crossed over to undergo real rTMS, following a $>4$-week washout period. Therefore, data on real rTMS were obtained from a total of eight patients. Patients and investigators (except the rTMS operator) were blinded to the form of stimulation.

Patients received five consecutive daily rTMS in the morning between 0800 and 1000 hours. A MagStim Super Rapid magnetic stimulator (Magstim Company, Whitland, UK) connected with a double cone (each wing measuring $110 \mathrm{~mm}$ in diameter) was held over the vertex.

For real rTMS, we applied 2-s-long bursts at $20 \mathrm{~Hz}$ with interstimulus interval of $28 \mathrm{~s}$, for a total of 1600 pulses over $20 \mathrm{~min}$. The intensity of stimulation was set at $90 \%$ of the resting motor threshold (RMT) intensity for induction of motor-evoked potentials (MEPs) in the right biceps brachii (BB) muscle, as this muscle was spared in all patients. For RMT determination, the coil was held over the optimal scalp position overlying the left hemisphere from which MEPs of maximal amplitude in the right BB were obtained. RMT was defined as the minimum stimulus intensity that produces MEP of $>50 \mu \mathrm{V}$ in $50 \%$ of 10 trials.

For sham stimulation, the double cone coil was held over the vertex (just as in the active TMS condition), but it was disconnected from the main stimulator unit. Instead, a second coil (8-shaped) was connected with the MagStim stimulator and discharged under the patient's pillow. Thus, no current was induced in the brain and, even if the patients did not experience an identical cutaneous sensation, they were exposed to a similar clicking noise.

The experimental design was similar to that employed by Kumru et al., ${ }^{4}$ and included the following steps: baseline clinical and neurophysiological evaluation immediately before the rTMS intervention; first rTMS session immediately followed by clinical and neurophysiological re-evaluation; daily rTMS sessions for 4 more days, clinical and neurophysiological re-evaluation immediately after the last of the fifth consecutive daily rTMS session; clinical and neurophysiological follow-up 1 week after the rTMS intervention.

Sham rTMS was applied only in subjects with SCI. We decided not to perform sham rTMS in the controls as we did not expect in healthy subjects any changes after rTMS and, consequently, no placebo effect to control for. Whereas electrophysiological parameters (reciprocal inhibition, Hmax/Mmax ratio) were evaluated in both patients and healthy subjects, the clinical values (MAS and SCAT) were measured only in the patients; in fact, these measurements by healthy subjects yield—by definition—ceiling values.

\section{Data analysis}

All statistical tests were performed in Matlab (The Mathworks, Natic, MA, USA).

First of all, we verified the crossover design by calculating Wilcoxon ranksum tests between the values measured during real rTMS in the four patients who underwent sham rTMS before real rTMS and those four patients who did not. Note that this is an altered version of the verification method as described by Wellek and Blettner, ${ }^{10}$ as we did not have a full crossover design. As such, the rank-sum tests revealed no difference between real rTMS only patients and crossed over patients for none of the measurement times and none of the response variables.

Reciprocal inhibition (the size of the conditioned soleus H-reflex, expressed as percentage of the unconditioned H-reflex test), SCAT and MAS scores, and Hmax/Mmax ratio were evaluated with the Friedman test as non-parametric one-way analysis of variance equivalent (using function myfriedman.m). ${ }^{11}$ This test assessed changes over assessment times (four repeated measures), separately for each group real rTMS, sham rTMS and healthy participants. The resulting $P$-values of all tests (that is, three groups for the reciprocal inhibition, two groups for MAS and two groups for SCAT, thus, in sum there were seven Friedman's tests) were corrected for multiple comparisons using the false-discovery rate correction as described by Benjamini and Hochberg, ${ }^{12}$ resulting in a critical level of significance with $P \leqslant 0.0013$. In case of a significant result, post hoc tests based on Fisher's method of the least significant distance were applied. These post hoc test results, by definition, can be interpreted at the $P<0.05$ level of significance, as the primary analysis already accounted for the multiple comparison problem.

Spearman correlation was used to test for a possible correlation between the clinical parameters MAS and SCAT, and the amount of reciprocal inhibition at each of the four time points in the real rTMS group. The resulting $P$-values were submitted to false-discovery rate correction, again, but the resulting $P$-value was even more strict than the Bonferroni-corrected $P$-value $(P<0.0063$ for eight correlations).

\section{RESULTS}

Spasticity was significantly (according to false-discovery rate correction) reduced after real rTMS intervention, as measured by both MAS ( chi-square $(3)=15.73 ; P=0.0013)$ and SCAT (chi-square $(3)=16.7$; $P=0.0008$ ), whereas Hmax/Mmax ratio did not change significantly over the four assessments (chi-square(3) $=5.06 ; P=0.17$ ). The descriptive statistics for all measurements are shown in Table 2. 
Table 2 Descriptive statistics of measured parameters for ordinalscaled MAS and SCAT values for the included groups

\begin{tabular}{|c|c|c|c|c|}
\hline Parameter/group & $\begin{array}{c}\text { Before } \\
\text { intervention }\end{array}$ & $\begin{array}{c}\text { After first } \\
\text { intervention }\end{array}$ & $\begin{array}{c}\text { After last } \\
\text { intervention }\end{array}$ & $\begin{array}{c}1 \text { Week } \\
\text { later }\end{array}$ \\
\hline \multicolumn{5}{|l|}{$\%$ of $\mathrm{H}$-reflex test } \\
\hline Real rTMS patients & $\begin{array}{c}101.88 \\
(8.49)\end{array}$ & $\begin{array}{l}92.63 \\
(9.05)\end{array}$ & $86.5(9.26)$ & $\begin{array}{l}95.25 \\
(7.94)\end{array}$ \\
\hline $\begin{array}{l}\text { Sham rTMS } \\
\text { patients }\end{array}$ & $101(8.37)$ & $\begin{array}{l}101.2 \\
(8.56)\end{array}$ & $\begin{array}{l}100.2 \\
(8.44)\end{array}$ & $\begin{array}{l}100.6 \\
(8.23)\end{array}$ \\
\hline Real rTMS controls & $84.63(9.75)$ & $84(9.68)$ & $\begin{array}{l}83.63 \\
(9.32)\end{array}$ & $\begin{array}{l}84.75 \\
(9.29)\end{array}$ \\
\hline \multicolumn{5}{|l|}{ Hmax/Mmax ratio } \\
\hline Real rTMS patients & $0.51(0.13)$ & $0.5(0.13)$ & $0.5(0.13)$ & $0.5(0.13)$ \\
\hline $\begin{array}{l}\text { Sham rTMS } \\
\text { patients }\end{array}$ & $0.5(0.17)$ & $0.49(0.17)$ & $0.5(0.17)$ & $0.5(0.18)$ \\
\hline \multicolumn{5}{|l|}{ MAS } \\
\hline Real rTMS patients & $3(2-4)$ & $2(1-3)$ & $1.5(1-2)$ & $2(1-3)$ \\
\hline $\begin{array}{l}\text { Sham rTMS } \\
\text { patients }\end{array}$ & $3(2-4)$ & $3(2-4)$ & $3(2-3)$ & $3(3-4)$ \\
\hline \multicolumn{5}{|l|}{ SCAT } \\
\hline Real rTMS patients & $5.5(3-9)$ & $4(2-7)$ & $4(2-6)$ & $4.5(3-7)$ \\
\hline $\begin{array}{l}\text { Sham rTMS } \\
\text { patients }\end{array}$ & $6(4-9)$ & $6(4-8)$ & $5(4-8)$ & $6(4-8)$ \\
\hline
\end{tabular}

Abbreviations: MAS, Modified Ashworth Scale; rTMS, repetitive transcranial magnetic stimulation; SCAT, Spinal Cord Injury Assessment Tool for Spasticity.

Data are presented as mean (s.d.) or median (range).

According to post hoc tests, MAS and SCAT values significantly decreased after the first intervention (MAS: $P<0.0001$; SCAT: $P<0.0001)$ and then significantly increased back towards the baseline SCI deficit at 1-week follow-up (MAS: $P=0.013$; SCAT: $P=0.01$ ), but this follow-up value was still significantly lower than that before the intervention (MAS: $P=0.0006$; SCAT: $P=0.0002$ ).

There was no significant effect on spasticity at any time point after sham rTMS (MAS: chi-square $(3)=2.54 ; \quad P=0.47 ;$ SCAT: chisquare $(3)=4 ; P=0.26 ; \mathrm{Hmax} / \mathrm{Mmax}$ ratio: chi-square $(3)=1.05$; $P=0.79$ ). Figures $1-3$ show the results of MAS, SCAT and Hmax/ Mmax ratio for both groups (real and sham rTMS), respectively.

Reciprocal inhibition differed significantly between healthy controls and patients at baseline $(\mathrm{W}(16)=41 ; P=0.003)$ and was significantly modified in patients during real rTMS intervention (chisquare $(3)=22.82 ; P=0.00004)$. The conditioned H-reflex significantly decreased after first and from first to last intervention $(P<0.0001)$ and then significantly increased back towards the baseline SCI deficit at 1 -week follow-up $(P<0.0001)$, but this follow-up value was still significantly lower than that before the intervention $(P<0.0001)$. The results are shown in Figure 4.

After sham stimulation, reciprocal inhibition was not significantly different at any time points (chi-square( 3$)=3.28 ; P=0.35$ ). In addition, there was no significant effect on reciprocal inhibition at any time point in healthy control subjects after real rTMS (chisquare( 3$)=4 ; P=0.26$ )

The correlation values of reciprocal inhibition and clinical parameters at each time point are shown in Table 3. None of the resulting $P$-values reached the Bonferroni-corrected level of significance $(P \leqslant 0.0063)$. However, the correlation values tended to be higher at the time before rTMS intervention than after rTMS intervention.

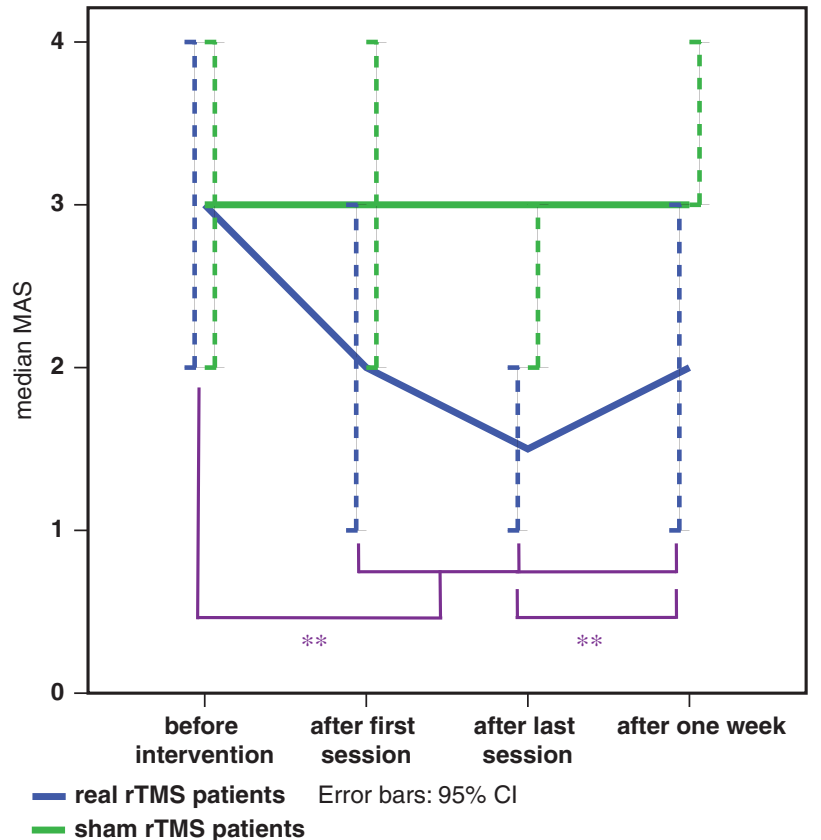

Figure 1 Median Modified Ashworth Scale (MAS) score after real and sham rTMS. ${ }^{*} P \leqslant 0.0013$ (corrected for multiple comparisons).

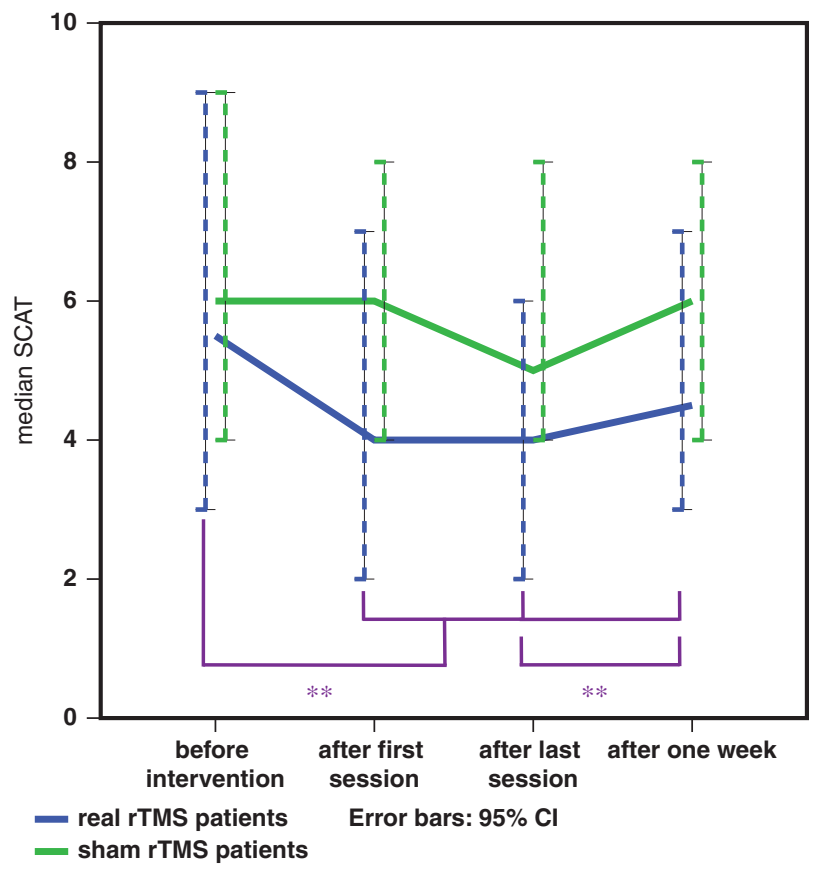

Figure 2 Median Spinal Cord Injury Assessment Tool for Spasticity (SCAT) score after real and sham rTMS. ${ }^{* *} P \leqslant 0.0013$ (corrected for multiple comparisons).

\section{DISCUSSION}

The salient finding of this study was that, we first demonstrated neurophysiological effects of rTMS on spinal neural circuits in SCI subjects with spasticity. By increasing motor cortex excitability, ${ }^{13}$ high-frequency rTMS modified corticospinal projections, resulting in an alteration of segmental spinal excitability. Impairment of 


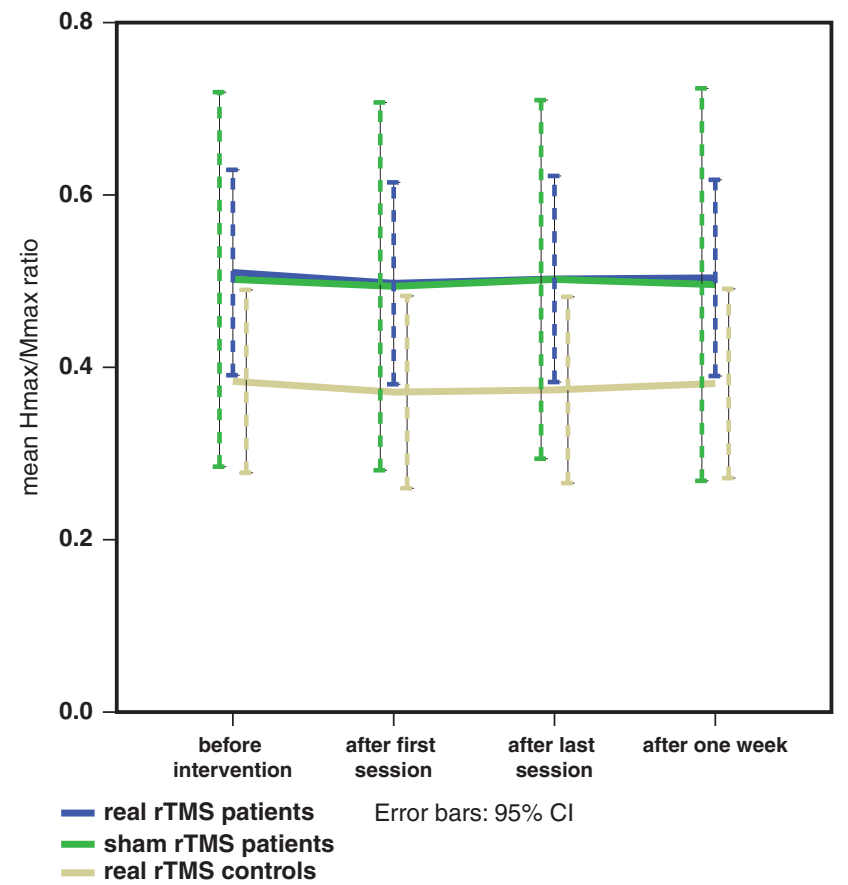

Figure 3 Mean Hmax/Mmax ratio after real and sham rTMS.

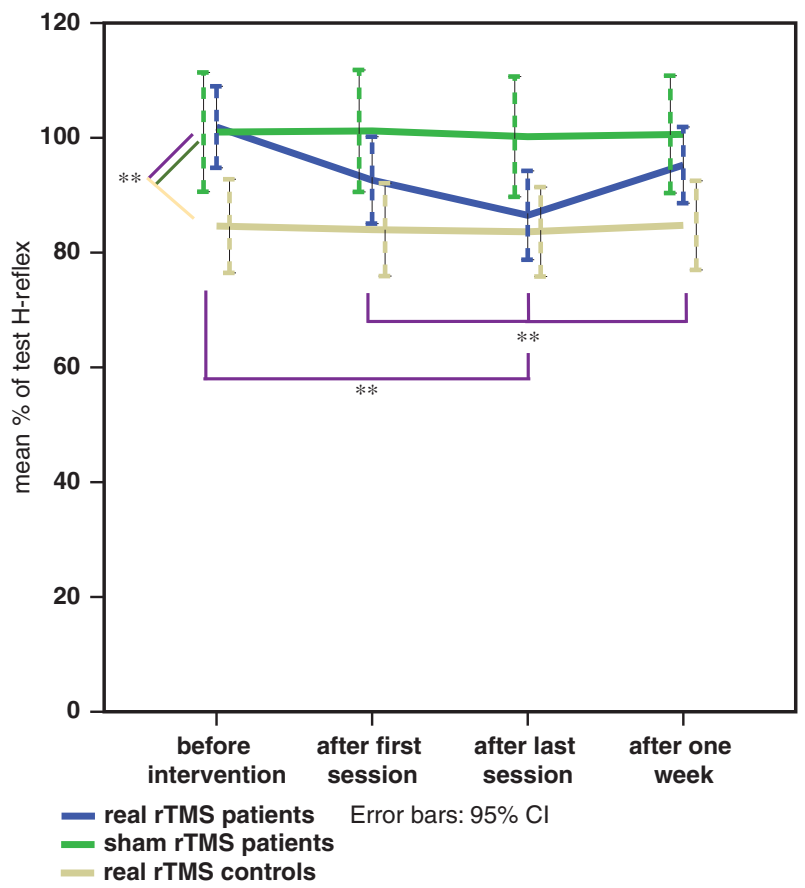

Figure 4 Reciprocal inhibition (expressed as \% of the test $\mathrm{H}$-reflex) before and after real and sham rTMS. ${ }^{*} P \leqslant 0.0013$ (corrected for multiple comparisons).

reciprocal inhibition has been suggested to have a causal role in the development of spasticity, ${ }^{6,14-17}$ and a decreased excitability in the disynaptic reciprocal inhibitory pathway has indeed been demonstrated in patients with spasticity of different origin. ${ }^{14,17,18}$

TMS studies in awake humans have already demonstrated cortical control of spinal reflex circuits. In fact, subthreshold TMS produces a
Table 3 Spearman's correlation of reciprocal inhibition with clinical parameters in the real rTMS patient group

\begin{tabular}{lcccc}
\hline Parameter & $\begin{array}{c}\text { Before } \\
\text { intervention }\end{array}$ & $\begin{array}{c}\text { After first } \\
\text { intervention }\end{array}$ & $\begin{array}{c}\text { After last } \\
\text { intervention }\end{array}$ & $\begin{array}{c}1 \text { Week } \\
\text { later }\end{array}$ \\
\hline MAS & $\mathrm{Rho}=0.82 ;$ & $\mathrm{Rho}=0.87 ;$ & $\mathrm{Rho}=0.66 ;$ & $\mathrm{Rho}=0.31 ;$ \\
SCAT & $P=0.018$ & $P=0.012$ & $P=0.086$ & $P=0.51$ \\
& $\mathrm{Rho}=0.79 ;$ & $\mathrm{Rho}=0.74 ;$ & $\mathrm{Rho}=0.73 ;$ & $\mathrm{Rho}=0.74 ;$ \\
& $P=0.025$ & $P=0.043$ & $P=0.047 ;$ & $P=0.05$ \\
\hline
\end{tabular}

Abbreviations: MAS, Modified Ashworth Scale; rTMS, repetitive transcranial magnetic stimulation; SCAT, Spinal Cord Injury Assessment Tool for Spasticity.

short-latency inhibition on the soleus H-reflex followed by a period of facilitation, ${ }^{19-21}$ whereas the TA H-reflex is facilitated at an early conditioning-test interval. ${ }^{22}$ Moreover, the TA long-latency (or M3) ankle stretch reflex is also facilitated when the MEP arrived in the spinal cord at the same time. ${ }^{22}$ By contrast, the long-latency TA stretch reflex is inhibited by subthreshold TMS intensities delivered $55-85 \mathrm{~ms}$ before the M3. The test H-reflex facilitation, induced by transcranial electrical stimulation applied to the scalp below the intensity needed to produce a motor response, was quickly terminated by subsequent arrivals of inhibitory postsynaptic potentials (IPSPs) at the motoneurons. ${ }^{19}$ These IPSPs might be produced by activity in Ia inhibitory interneurons, which in monkeys receive monosynaptic tract projections. ${ }^{23}$

The interneurons interposed in the disynaptic reciprocal inhibitory pathway are activated by the corticospinal tract in both monkey ${ }^{24}$ and humans, ${ }^{19-22}$ and are strongly facilitated by supraspinal commands before and at the onset of agonist contraction. ${ }^{2}$ This supraspinal facilitation is impaired in patients with spasticity, ${ }^{15}$ and decreased supraspinal control of interneurons in the disynaptic reciprocal inhibitory pathway has thus been suggested as one critical contributing factor to the development of spasticity. On the other hand, the observed results cannot exclusively be attributed to a direct corticospinal tract influence over reciprocal inhibition, and multiple other corticospinal pathways could be involved. In particular, the corticoreticulospinal pathway is thought to be the primary means of conveying locomotor command signals from higher motor centre to spinal interneuronal circuits, ${ }^{25}$ and may subserve functional recovery after corticospinal lesions. ${ }^{26}$

The decrease in spasticity induced by rTMS may thus be due to a strengthening of the descending projections and segmental effect of spinal interneurons. ${ }^{1}$ Increasing the excitability of the M1 would modify descending corticospinal influences and increase inhibitory input, which would then reduce segmental spinal excitability and thus reduce limb spasticity in patients with incomplete SCI.

Animal studies employing intracellular recordings from motoneurons provided a detailed knowledge of the pathway and integration of segmental and supraspinal convergence at the interneuronal level. ${ }^{27,28}$ Volleys in the corticospinal tract exert an excitatory action on interneurones of reflex arc, in particular Ia inhibitory interneurons. ${ }^{29}$ In monkeys, intracortical stimulation revealed that the same interneurons mediate the disynaptic inhibition of motoneurons evoked by the projections of pyramidal tract cells and the disynaptic inhibition of motoneurons evoked by group Ia afferents of antagonist muscles. ${ }^{24}$ Moreover, motoneurons and Ia inhibitory interneurons were activated in parallel by supraspinal centres in order to secure a coordinated contraction of agonists and relaxation of antagonists. ${ }^{30}$ 
The results of the present study support and extend previous findings demonstrating the beneficial effects of rTMS on spasticity in patients with SCI. Directions for future research might include exploring longer course of rTMS in larger number of patients or measuring reciprocal inhibition in response to other interventions against spasticity, such as drugs.

\section{DATA ARCHIVING}

There were no data to deposit.

\section{CONFLICT OF INTEREST}

The authors declare no conflict of interest.

1 Valero-Cabre A, Oliveri M, Gangitano M, Pascual-Leone A. Modulation of spinal cord excitability by subthreshold repetitive transcranial magnetic stimulation of the primary motor cortex in humans. Neuroreport 2001; 12: 3845-3848.

2 Centonze D, Koch G, Versace V, Mori F, Rossi S, Brusa L et al. Repetitive transcranial magnetic stimulation of the motor cortex ameliorates spasticity in multiple sclerosis. Neurology 2007; 68: 1045-1050.

3 Valle AC, Dionisio K, Pitskel NB, Pascual-Leone A, Orsati F, Ferreira MJ et al. Low and high frequency repetitive transcranial magnetic stimulation for the treatment of spasticity. Dev Med Child Neurol 2007; 49: 534-538.

4 Kumru H, Murillo N, Samso JV, Valls-Sole J, Edwards D, Pelayo R et al. Reduction of spasticity with repetitive transcranial magnetic stimulation in patients with spinal cord injury. Neurorehabil Neural Repair 2010; 24: 435-441.

5 Crone $\mathrm{C}$, Hultborn $\mathrm{H}$, Jespersen $\mathrm{B}$, Nielsen J. Reciprocal la inhibition between ankle flexors and extensors in man. J Physiol 1987; 389: 163-185.

6 Crone C, Nielsen J. Central control of disynaptic reciprocal inhibition in humans. Acta Physiol Scand 1994; 152: 351-363.

7 Marino RJ, Barros T, Biering-Sorensen F, Burns SP, Donovan WH, Graves DE et al. ASIA Neurological Standards Committee. International standards for neurological classification of spinal cord injury. J Spinal Cord Med 2002; 26: S50-S56.

8 Bohannon RW, Smith MB. Interrater reliability of a modified Ashworth scale of muscle spasticity. Phys Ther 1987; 67: 206-207.

9 Benz EN, Hornby TG, Bode RK, Scheidt RA, Schmit BD. A physiologically based clinical measure for spastic reflexes in spinal cord injury. Arch Phys Med Rehabil 2005; 86: 52-59.

10 Wellek S, Blettner M. On the proper use of the crossover design in clinical trials: Part 18 of a series on evaluation of scientific publications. Dtsch Arztebl Int 2012; 109: 276-281.

11 Cardillo G. MyFriedman: Friedman test for non parametric two way analysis of variance. Matlab Central File exchange. Accessed online on 18 September 2013.
12 Benjamini Y, Hochberg Y. Controlling the false discovery rate: a practical and powerful approach to multiple testing. J R Stat Soc 1995; 57: 289-300.

13 Peinemann A, Reimer B, Löer C, Quartarone A, Münchau A, Conrad B et al. Long-lasting increase in corticospinal excitability after 1800 pulses of subtheshold $5 \mathrm{~Hz}$ repetitive TMS to the primary motor cortex. Clin Neurophysiol 2004; 115: 1519-1526.

14 Yanagisawa N, Tanaka R, Ito Z. Reciprocal la inhibition in spastic hemiplegia of man. Brain 1976; 99: 555-574.

15 Nakashima K, Rothwell JC, Day BL, Thompson PD, Shannon K, Marsden CD. Reciprocal inhibition between forearm muscles in patients with writer's cramp and other occupational cramps, symptomatic hemidystonia and hemiparesis due to stroke. Brain 1989; 112: 681-697.

16 Crone C, Nielsen J, Petersen N, Ballegaard M, Hultborn H. Disynaptic reciprocal inhibition of ankle extensors in spastic patients. Brain 1994; 117: 1161-1168.

17 Morita H, Crone C, Christenhuis D, Petersen NT, Nielsen JB. Modulation of presynaptic inhibition and disynaptic reciprocal la inhibition during voluntary movement in spasticity. Brain 2001; 124: 826-837.

18 Crone C, Johnsen LL, Biering-Sorensen F, Nielsen JB. Appearance of reciprocal facilitation of ankle extensors from ankle flexors in patients with stroke or spinal cord injury. Brain 2003; 126: 495-507.

19 Cowan JMA, Day BL, Marsden C, Rothwell JC. The effect of percutaneous motor cortex stimulation on $\mathrm{H}$ reflexes in muscles of the arm and leg in intact man. J Physiol 1986; 377: 333-347.

20 Iles JF, Pisini JV. Cortical modulation of transmission in spinal reflex pathways of man. J Physiol 1992; 455: 425-446.

21 Nielsen J, Petersen N. Evidence favouring different descending pathways to soleus motoneurones activated by magnetic brain stimulation in man. J Physiol 1995; 486: 779-788.

22 Petersen N, Christensen LOD, Morita H, Sinkjær T, Nielsen J. Evidence that a transcortical pathway contributes to stretch reflexes in the tibialis anterior muscle in man. J Physiol 1998; 512: 267-276.

23 Jankowska E, Tanaka R. Neuronal mechanism of the disynaptic inhibition evoked in primate spinal motoneurones from the corticospinal tract. Brain Res 1974; 751: 163-166.

24 Jankowska E, Padel Y, Tanaka R. Disynaptic inhibition of spinal motoneurones from the motor cortex in the monkey. J Physiol 1976; 258: 467-487.

25 Matsuyama K, Mori F, Nakajima K, Drew T, Aoki M, Mori S. Locomotor role of the corticoreticular-spinal interneuronal system. Prog Brain Res 2004; 143: 239-249.

26 Zaaimi B, Edgley SA, Soteropoulos DS, Baker SN. Changes in descending motor pathway connectivity after corticospinal tract lesion in macaque monkey. Brain 2012; 135: 2277-2289.

27 Eccles JC, Fatt P, Landgren S. The inhibitory pathway to motoneurones. Prog Neurobiol 1956; 2: 72-82.

28 Hultborn H, Illert M, Santini M. Convergence on interneurones mediating the reciprocal la inhibition of motoneurones. III. Effects from supraspinal pathways. Acta Physiol Scand 1976: 96: 368-391.

29 Lundgren A, Voorhoeve P. Effects from the pyramidal tract on spinal reflex arcs. Acta Physiol Scand 1962; 56: 201-219.

30 Lundberg A. Supraspinal control of transmission in reflex paths to motoneurones and primary afferents. Prog Brain Res 1964; 12(C), 197-221. 